\title{
GORONG-GORONG SEBAGAI MEDIA FILTER AIR BERSIH
}

\author{
Ida Zuraida ${ }^{1 凶}$, Wattini $^{2}$, Nizar $^{3}$ \\ ${ }^{1,2,3}$ Afiliasi , Jurusan Teknik Sipil, Politeknik Negeri Pontianak, \\ Jl. Ahmad Yani Pontianak, kode Pos.78124 \\ ${ }^{\square}$-mail : zuraida_lab@yahoo.co.id
}

\begin{abstract}
Clean water with clear criteria, odorless, colorless and tasteless, fulfilled by the local government has limited services. The research scope includes making wells to making water filters. The output system is in the form of water which is tested for its clarity and turbidity level in the laboratory. In this research, the stages carried out are making wells, making intake systems, distribution systems to filters, making filter systems with three models, testing and evaluation, sampling and testing. The results of the research were in the form of filter work and water quality. The quality of the initial period with clarity parameters between $46.8-55.5 \mathrm{mg} / \mathrm{l}$ with a percentage decrease of $7 \%$, while with the turbidity parameter between 157 - $227 \mathrm{NTU}$, the percentage decrease was 12\%. Mid-period quality with clarity parameters between 52.4 - $65 \mathrm{mg} / \mathrm{l}$ with a decrease percentage of $0 \%$, while with turbidity parameters between 32.5 - 151 NTU with a decrease percentage between 0 - 79\%. Quality at the end of the period with clarity parameter $4.3 \mathrm{mg} / \mathrm{l}$ with a percentage decrease of 5\% while the turbidity parameter was between $88.7-109 \mathrm{NTU}$ with a decrease percentage between 20 - 35\%. The initial hope of the culvert can be penetrated by water but the reality in the field is not achieved. The second hope of directing the water flow from the bottom up through the sand medium was also not achieved. The only hope is through the bottom of the culvert which can still be penetrated by water and can filter the water a little bit, but this is also ineffective because when it opens per model it causes piping. This research is still not perfect, it still needs to be developed so that it can be applied.
\end{abstract}

Keyword : Culvert, filter media, clean water.

\begin{abstract}
Abstrak
Air bersih dengan kreteria jernih, tidak berbau, tidak berwarna dan tidak berasa, dipenuhi oleh pemerintah setempat memiliki keterbatasan layanan. Lingkup penelitian meliputi membuat sumur sampai membuat filter air. Ouput system berupa air yang diuji tingkat kejemihan dan tingkat kekeruhannya di Laboratorium. Dalam penelitian ini tahapan yang dilakukan yaitu pembuatan sumur, pembuatan system intake, system distribusi ke filter, pembuatan system filter dengan tiga model, ujicoba dan evaluasi, pengambilan sampel dan pengujian. Hasil penelitian berupa karya cipta filter dan kualitas air. Kualitas periode awal dengan parameter kejernihan antara 46,8 - 55,5 mg/l dengan prosentase penurunan sebesar 7\% sedangkan dengan parameter kekeruhan antara $157-227$ NTU, prosentase penurunan sebesar 12\%. Kualitas periode pertengahan dengan parameter Kejernihan antara 52,4-65 mg/l dengan prosentase penurunan 0\% sedangkan dengan parameter Kekeruhan antara 32,5 - 151 NTU dengan prosentase penurunan sebesar antara $0-79 \%$. Kualitas periode akhir dengan parameter Kejernihan 4,3 mg/l dengan prosentase penurunan sebesar $5 \%$ sedangkan parameter Kekeruhan antara 88,7 - 109 NTU dengan prosentase penurunan antara 20 -35\%. Harapan awal gorong-gorong dapat ditembus oleh air tetapi kenyataan dilapangan tidak tercapai. Harapan kedua untuk mengarahkan aliran air dari bawah keatas melalui media pasir juga tidak tercapai. Harapan satu-satunya yaitu melalui bagian dasar gorong-gorong yang masih bisa ditembus oleh air dan agak sedikit bisa menyaring air tetapi ini juga tidak efektif karena pada saat open per model menimbulkan piping. Penelitian ini masih belum sempurna, masih perlu dilakukan pengembangan agar bisa diterapkan.
\end{abstract}

Kata Kunci : Gorong-gorong, media filter, air bersih 


\section{Pendahuluan}

Air bersih sebagai kebutuhan harus memenuhi kriteria jemih, tidak berbau, tidak berwama dan tidak berasa.

Dalam pemenuhannya biasanya dipenuhi oleh pemerintah setempat terkadang memiliki keterbatasan sehingga tidak semua lapisan masyarakat dapat terlayani air bersih, ini bisa disebabkan oleh kapasitas system penyediaan yang terbatas, jarak tempuh ke lokasi masyarakat agak terpencil dan ketersediaan air baku yang terbatas.

Tujuan penelitian yaitu mendapat air melalui penyediaan secara mandiri dengan membuat filter air dari goronggorong yang tersedia dipasaran.

Manfaat bagi masyarakat yaitu dapat langsung diterapkan. Bagi Pemerintah bermanfaat untuk membantu dalam hal pelayanan air bersih kepada Masyarakat.

\section{Metode Penelitian}

Metoda penelitian terdiri beberapa tahapan yaitu : a) Persiapan, memasang system pipa Intake di sumur sumber air baku, mamasang jaringan pipa penghantar dari pipa intake ke pompa air, memasang system pipa distribusi dari pompa ke system filter gorong-gorong, mengerjakan system filter goronggorong. System filter terdiri dari tiga model dengan model seperti digambarkan pada Gambar 1. b) Ujicoba, melakukan ujicoba terhadap fungsionalitas system, dalam ujicoba diambil data debit dengan perlakuan operasi secara serentak dan operasi per model filter. c) Pengukuran dan Pengambilan sampel, berupa debit air pada output filter (hasil) dan drainase filter; Pengambilan sampel pasir filter berupa pasir kasar dan pasir halus untuk uji permeabilitas dilaboratorium; Pengambilan sampel air untuk uji kejernihan (TDS) dan kekeruhan (TSS). Sampel air terdiri dari tiga jenis yaitu :
Sampel sumber air baku, output filter (hasil) dan air drainase.

Sampel air yang diambil terdiri atas tiga periode pengambilan yaitu :

Periode awal (6 September 2020), data diambil pada kondisi bahan media masih apa adanya, masih belum bersih, masih belum dilewati oleh air secara kontinyu, masih ada pengaruh debu yang menempel.

Periode pertengahan (12 September 2020), data diambil dengan kondisi system dalam keadaan sudah dilewati oleh air secara berulang-ulang, kotoran, sedimen-sediamen sudah keluar melalui system output filter dan system drainase. Periode akhir (5 Oktober 2020), data akhir diambil setelah system filter dalam kondisi sudah mengalami ptoses pembuangan sedimen-sedimen dan mineral-mineral secara alami melalui system.

Sampel air diambil dan diuji di laboratorium dengan parameter Total Dissolved Solid (TDS) dan Total Suspended Solid (TSS). Data dibandingkan antara satu jenis sampel dengan jenis sampel lainnya dan perbandingan antara air sumber baku dengan output filter (hasil) dan drainase serta perbandingan data antar periode pengambilan untuk mengetahui apakah ada perkembangan atau perubahan kearah menjadi lebih baik. d) Analisa Data, data hasil uji dilaboratorium kemudian dianalisa seberapa besar pengaruh air baku setelah melewati system filter dan drainase. e) Kesimpulan, barometer atas keberhasilan penelitian ini jika air yang keluar dari filter lebih jernih dari air baku. Untuk lebih jelas dapat dilihat pada Gambar 2.

\section{Hasil dan Pembahasan}

Hasil penelitian berupa system filter mulai dari sumber air baku, system intake, system penghantar dari intake ke 
pompa, dari pompa ke system distribusi ke system filter gorong-gorong. Goronggorong disini terdiri dari tiga model seperti Gambar 3.

\section{Dimensi gorong-gorong}

Gorong-gorong buatan masyarakat dimensinya tidak presisi sehingga berpengaruh terhadap isolasi kedap air (Tabel 1).

\section{Permeability gorong-gorong}

Permeabilitas terhadap gorong-gorong hanya terdapat pada Model B yang memiliki nilai $=0,00333 \mathrm{~m} / \mathrm{det}$ dan model yang lainnya $=$ nol atau tidak tembus air (lihat Tabel 2),.

\section{Permeability media pasir}

Permeabilitas $(\mathrm{k})$ terhadap media mulai dari Pasir Kasar, Pasir Halus dan gabungan Pasir Kasar dan Halus (lihat Tabel 3). Penerapan menggunakan variasi dua jenis media Pasir Kasar + Halus. Ada dua perbedaan yang mencolok yaitu pola aliran dari Bawah ke Atas (BA) dan dari Atas ke Bawah (AB) dengan nilai seperti pada Gambar 4.

Pola aliran dari bawah ke atas nilai terendah $=0,55 \mathrm{~cm} /$ det dan maksimum $=$ $0,83 \mathrm{~cm} /$ det, sedangkan pada pola aliran dari atas ke bawah nilai terendah $=4,67$ $\mathrm{cm} /$ det dan tertinggi $=5,50 \mathrm{~cm} /$ det .

Penerapan nilai $\mathrm{k}$ untuk perencanaan diambil nilai yang terendah dari media gabungan pasir kasar dan halus dengan pola aliran dari Bawah ke Atas (BA) dengan alasan karena dalam penerapan dilapangan diterapkan dengan debit sepertiga dari debit minimum dari kapasitas pompa yaitu sepertiga dari 18 $1 / \mathrm{min}=61 / \mathrm{min}$ atau $=0,0001 \mathrm{~m}^{3} /$ det.

Debit rencana pada masing-masing model seperti ditampilkan pada Tabel 4, dengan rumus $\mathrm{Q}=\mathrm{k}$. A
Dimana :

$\mathrm{Q}=$ Debit air, $\mathrm{m}^{3} / \mathrm{det}$

$\mathrm{k}=$ Koefesien Permeability (Lab), m/det

$\mathrm{A}=$ Luas penampang media pasir, $\mathrm{m}^{2}$

\section{Debit filter gorong-gorong (Q)}

Debit filter ada dua jenis yaitu debit yang dihasilkan dari output filter (hasil) masing-masing model dan debit drainase.

Debit output filter (hasil), Tabel 5, debit yang terbesar terdapat pada Model $\mathrm{C}=$ $0,00620 \mathrm{~m}^{3} /$ det sedangkan debit yang terkecil pada Model $\mathrm{A}=\mathbf{0 , 0 0 1 0 5} \mathbf{~ m}^{\mathbf{3}} / \mathbf{d e t}$. Debit pada Model A paling kecil disebabkan pada dasar gorong-gorong ada urugan pasir setinggi lebih kurang $16,2 \mathrm{~cm}$ sedangkan pada model yang lain tidak ada.

Jika dibandingkan antara debit rencana berdasarkan dengan nilai $\mathrm{k}$ hasil percobaan dilaboratorium (Tabel 3) dan debit hasil pengukuran dilapangan (Tabel 5) menunjukan bahwa debit yang dihasilkan dilapangan lebih besar antara $0,00105-0,00620 \mathrm{~m}^{3} /$ det dari pada berdasarkan pada perhitungan antara $0,00030-0,00031 \mathrm{~m}^{3} /$ det.

Debit lapangan lebih besar dari Debit hitungan disebabkan oleh bagian dasar gorong-gorong yang tidak rata dengan sempurna.

Drainase filter berfungsi sebagai system pembuangan sedimen-sedimen kasar yang tidak mampu menembus dinding gorong-gorong dan media pasir. System dioperasikan secara serentak tiga model dengan bukaan stopkran diatur hanya separuh bukaan untuk maksud ada tekanan kearah dinding gorong-gorong dan melalui media pasir.

Debit yang terukur pada Tabel 6, terlihat bahwa debit terbesar terdapat pada Model $\mathrm{C}=0,000205 \mathrm{~m}^{3} / \mathrm{det}$ dan debit yang terkecil pada Model A yaitu 0,000148 $\mathrm{m}^{3} /$ det. 
Debit Draianse (Tabel 6) yang beroperasi secara serentak kesemua Model Filter tetapi pada operasi secara per Model Filter mengakibatkan piping sehingga dalam hal ini debitnya tidak bisa diukur secara berkelanjutan.

\section{Uji sampel air}

Berdasarkan periode waktu Sampel air terdiri dari tiga periode yaitu Periode Awal, Periode Pertengahan dan Periode Akhir.

Sampel air yang diambil berdasarkan tempat dan periode waktu diukur dengan parameter Total Dissolved Solid (TDS) dan parameter Total Suspended Solid (TSS). TDS diukur dengan metoda Condutivitymeter dan TSS diukur dengan metoda Turbiditymeter. Sampel yang diambil total 24 sampel yang terdiri dari Sumber air baku berjumlah 7 sampel, Output filter (hasil) 9 sampel dan Drainase 8 sampel. Kesemua sampel tersebut diambil dan diuji di Laboratorium.

Kualitas air Periode Awal dengan parameter TDS air baku sebesar $=50-$ $50,2 \mathrm{mg} / \mathrm{l}$, Hasil = 46,8 $-55,5 \mathrm{mg} / \mathrm{l}$ dan Drainase $=45,9-47 \mathrm{mg} / \mathrm{l}$; Prosentase mampu Hasil Model A = 7\%, Model B = $-9 \%$ dan Model $\mathrm{C}=-11 \%$; Prosentase mampu Drainase 6\% - 8\%.

Dengan parameter TSS air baku sebesar $=$ 179 NTU, Hasil = 157 NTU -227 NTU dan Drainase $=85,1$ NTU -105 NTU; Prosentase mampu Hasil Model A = 14\%, Model B $=\mathbf{1 2 \%}$ dan Model $\mathrm{C}=$ 27\%; Prosentase mampu Drainase untuk semua Model filter $=41 \%-52 \%$

Kualitas Air Periode Pertengahan dengan parameter TDS air baku sebesar 42,1 $\mathrm{mg} / \mathrm{l}-50,1 \mathrm{mg} / \mathrm{l}$, Hasil = 52,4 mg/l - 65 $\mathrm{mg} / \mathrm{l}$ dan Drainase $=49,6 \mathrm{mg} / \mathrm{l}-60,2$ $\mathrm{mg} / \mathrm{l}$; Prosentase mampu Hasil pada Model A $=-14 \%$, Model B $=-41 \%$ dan
Model $\mathrm{C}=-16 \%$; Prosentase mampu Drainase antara $-31-(-8 \%)$.

Dengan parameter TSS air baku sebesar $=$ 141 NTU - 162 NTU, Hasil = 32,5 NTU -151 NTU dan Drainase $=135$ NTU 199 NTU; Prosentase mampu Hasil Model A $=79 \%$, Model B $=21 \%$, Model $\mathrm{C}=0 \%$; Prosentase mampu Drainase pada Model $\mathbf{A}=\mathbf{1 1 \%}$, Model $\mathrm{B}=-31 \%$ dan Model $\mathrm{C}=-31 \%$.

Kualitas Air Periode Akhir dengan parameter TDS air baku sebesar 4,2 mg/l - 4,7 mg/l, Hasil = 4,3 mg/l dan Drainase $=4,4 \mathrm{mg} / \mathrm{l}$; Prosentase mampu Hasil pada Model A $=5 \%$, Model B $=5 \%$ dan Model $\mathbf{C}=\mathbf{5} \%$; Prosentase mampu Drainase $3 \%$.

Dengan parameter TSS air baku sebesar $=$ 127 NTU - 142 NTU, Hasil = 88,7 NTU -109 NTU dan Drainase $=138$ NTU 151 NTU; Prosentase mampu Output filter Model $\mathrm{A}=27 \%$, Model $\mathrm{B}=20 \%$, Model $\mathbf{C}=35 \%$; Prosentase mampu Drainase pada Model A = -1\%, Model B $=-10 \%$ dan Model $\mathrm{C}=-10 \%$.

Prosentase kemampuan menurunkan nilai parameter sampel air dari perbandingan sumber air baku dan hasil tersebut bervariasi ada yang turun dan ada yang naik, yang turun ditunjukkan dengan nilai minus menandakan adanya peningkatan kadar nilai TDS dan TSS dari air baku, ini dipengaruhi oleh adanya usaha pembersihan endapan lumpur yang melayang-layang didalam air pada wadah Baskom.

Untuk lebih jelas terkait dengan kualitas air terukur dengan parameter tersebut dapat dilihat pada Gambar 5 dan Gambar 6. Sedangan prosentase kemampuan menurunkan nilai dari air baku dapat dilihat pada Gambar 7 dan Gambar 8.

\section{KESIMPULAN DAN SARAN}

\section{Kesimpulan}

Harapan awal gorong-gorong dapat ditembus oleh air tetapi kenyataan 
dilapangan hanya gorong-gorong pada Model B yang mampu ditembus oleh air yaitu sebesar $=0,00333 \mathrm{~m} /$ det. Harapan kedua untuk mengarahkan aliran air dari bawah keatas melalui media pasir juga tidak tercapai karena isolasi bagian dasar gorong-gorong terhambat oleh bibir gorong-gorong yang tidak rata sempurna. Harapan satu-satunya yaitu melalui bagian dasar gorong-gorong yang masih bisa ditembus oleh air (Model B dan Model C), tetapi pada Model A agak sedikit bisa menyaring air tetapi ini juga tidak efektif karena pada saat open per Model menimbulkan piping.

- Periode Awal, prosentasi mampu terbaik dengan parameter TDS terdapat pada Model $\mathrm{A}=7 \%$ dan parameter TSS terdapat pada Model $\mathrm{B}=12 \%$.

- Periode Pertengahan, prosentasi mampu terbaik dengan parameter TDS tidak ada, sedangkan dengan parameter TSS terdapat pada Model $\mathrm{A}=79 \%$.

- Periode Akhir, prosentaase mampu terbaik dengan parameter TDS terdapat pada semua model (Model A, Model B dan Model C) $=5 \%$, sedangkan dengan parameter TSS prosentase mampu terbaik terdapat pada Model $\mathrm{C}=35 \%$.

Berdasarkan pada tiga periode pengambilan dan pengujian sampel dilaboratorium didapat data bahwa prosentase keberhasilan masing-masing periode beragam untuk periode awal tingkat keberhasilan hanya $7-12 \%$ dengan parameter TDS dan TSS, pada periode pertengahan tingkat keberhasilan melebihi dari periode awal yaitu $79 \%$ dengan parameter hanya TSS sedangkan pada periode akhir tingkat keberhasilannya antara $5-35 \%$ dengan rincian $\mathrm{TDS}=5 \%$ dan $\mathrm{TSS}=35 \%$.

Jadi yang dapat dijadikan pedoman terhadap tingkat keberhasilan adalah pada periode akhir karena pada periode ini system sudah dalam keadaan matang artinya sudah melalui proses pengaliran yang lama.

\section{Saran}

Untuk lebih effesien dalam penerapan gorong-gorong sebagai media filter maka ada beberapa point saran :

- Untuk Filter Model A, pada muka urugan pasir perlu diberi lantai muka untuk menahan agar pasir urug tidak hanyut terbawa oleh air.

- Untuk Filter Model B dan C pada dasar gorong-gorong perlu diperkuat isolasi dengan lapisan lantai cor untuk mengatasi bocor pada dasar goronggorong dan dengan demikian aliran bisa diarahkan dari Bawah ke Atas melalui media pasir, disamping itu diharapkan ada tekanan kearah dinding gorong-gorong.

- Untuk lebih memaksimalkan fungsi gorong-gorong agar dapat ditembus oleh air maka model gorong baiknya didesain dan dibuat sendiri dengan perbandingan campuran yang mampu ditembus oleh air.

- Penelitian yang dilakukan kali ini menganut pola aliran dari Bawah ke Atas tapi kalau memungkinkan bisa dilakukan penelitian lanjutan ke penelitian berikutnya dengan pola aliran dari Atas ke Bawah dengan maksud dan tujuan agar apa yang telah dilakukan dalam penelitian ini benarbenar bisa diterapkan oleh masyarakat secara langsung.

\section{Ucapan Terima kasih}

Terima kasih kami ucapkan kepada Lembaga Penelitian dan Pengabdian Pada Masyaraka (PPM) Politeknik Negeri Pontianak yang telah memberikan support finansial dalam kegiatan penelitian ini dan pihak-pihak yang terlibat dalam kegiatan tersebut. 
Ida Zuraida, dkk., Gorong-Gorong sebagai Media...

\section{Daftar Pustaka}

[1] Ida Zuraida.,Ir 2001, “ Penyediaan Air Bersih “, POLNEP.

[2] Ida Zuraida, dkk. 2018. "Pengaruh Komposisi Media Filter Air Terhadap Permeabilitas dan Clatitas". Jurnal POLI-
TEKNOLOGI. 2018. Volume 17. Nomor 1 Januari 2017.

[3] Kalimantan Barat Dalam Angka 2010, 2010, Badan Pusat Statistik Propinsi Kalimantan Barat.

[4] Widarto, L., Ir., 1996, “Membuat Alat Penjernih Air", Kanisius. 
Tabel 1. Dimensi Gorong-gorong

\begin{tabular}{ccccc}
\hline \multirow{2}{*}{ Model Filter } & \multicolumn{4}{c}{ Dimensi Gorong-gorong } \\
\cline { 2 - 5 } & $\begin{array}{c}\varnothing \text { dalam } \\
\mathbf{d 1}(\mathbf{c m})\end{array}$ & $\begin{array}{c}\text { tebal } \\
\mathbf{t}(\mathbf{c m})\end{array}$ & $\begin{array}{c}\varnothing \text { luar } \\
\mathbf{d} 2(\mathbf{c m})\end{array}$ & $\begin{array}{c}\text { tinggi } \\
\mathbf{h}(\mathbf{c m})\end{array}$ \\
\hline Model A & 31,00 & 4,80 & 40,60 & 100 \\
\hline Model B & 31,30 & $3,9-4,5$ & $39,1-40,3$ & 100 \\
\hline Model C & $30,9-31,2$ & $3,8-5,4$ & $38,5-42,0$ & 100 \\
\hline
\end{tabular}

Tabel 2. Pengukuran Permeabilitas Menembus Dinding Gorong-gorong

\begin{tabular}{cc}
\hline Model Filter & $\begin{array}{c}\text { Permeabilitas Gorong-gorong } \\
\mathbf{m} / \mathbf{d e t}\end{array}$ \\
\hline Model A & 0,00000 \\
\hline Model B & 0,00333 \\
\hline Model C & 0,00000 \\
\hline
\end{tabular}

Tabel 3. Pengukuran Nilai Permeabilitas di Laboratorium Dengan Dua Pola

\begin{tabular}{|c|c|c|c|c|c|c|}
\hline \multirow[t]{2}{*}{ Jenis Media } & \multirow[t]{2}{*}{ Pola Aliran } & \multirow{2}{*}{ 嶽 } & \multirow{2}{*}{ 苞 } & \multicolumn{3}{|c|}{$\begin{array}{c}\text { Variasi Debit }(\mathbf{Q}), \\
\mathrm{cm}^{3} / \text { det }^{2}\end{array}$} \\
\hline & & & & 6,67 & 5,00 & 3,33 \\
\hline \multirow{2}{*}{$\begin{array}{c}\text { Pasir Kasar } \\
8 \text { September } 2020\end{array}$} & Bawah ke Atas & \multirow{6}{*}{$\mathrm{k}$} & \multirow{6}{*}{$\mathrm{cm} / \operatorname{det}$} & 0,69 & 0,63 & 0,65 \\
\hline & Atas ke Bawah & & & 9,13 & 5,13 & 6,23 \\
\hline \multirow{2}{*}{$\begin{array}{c}\text { Pasir Halus } \\
9 \text { September } 2020\end{array}$} & Bawah ke Atas & & & 0,77 & 0,58 & 0,45 \\
\hline & Atas ke Bawah & & & 4,32 & 5,38 & 5,79 \\
\hline \multirow{2}{*}{$\begin{array}{l}\text { Pasir Kasar + Halus } \\
24 \text { September } 2020\end{array}$} & Bawah ke Atas & & & 0,83 & 0,67 & 0,55 \\
\hline & Atas ke Bawah & & & 4,67 & 5,09 & 5,50 \\
\hline
\end{tabular}

Tabel 4. Debit Minimum Rencana Dengan Pola Aliran Dari Bawah Ke Atas

\begin{tabular}{cc}
\hline Model Filter & $\begin{array}{c}\text { Qmin (BA) } \\
\mathbf{m}^{3} / \mathbf{d e t}\end{array}$ \\
\hline Model A & 0,00030 \\
\hline Model B & 0,00031 \\
\hline Model C & 0,00030 \\
\hline
\end{tabular}

Tabel 5. Debit Hasil Operasional Serentak Tiga Model

\begin{tabular}{cccc}
\hline Model Filter & $\begin{array}{c}\text { Volume Bersih } \\
\text { Output Filter } \\
\mathbf{V}\left(\mathbf{m}^{\mathbf{3}}\right)\end{array}$ & $\begin{array}{c}\text { Waktu tempuh } \\
\mathbf{t}(\mathbf{d e t i k})\end{array}$ & $\begin{array}{c}\text { Debit air } \\
\text { Output Filter } \\
\mathbf{Q}\left(\mathbf{m}^{\mathbf{3}} / \mathbf{d e t}\right)\end{array}$ \\
\hline Model A & 0,0152 & 14,45 & 0,00105 \\
\hline Model B & 0,0330 & 5,47 & 0,00603 \\
\hline Model C & 0,0321 & 5,17 & 0,00620 \\
\hline
\end{tabular}


Ida Zuraida, dkk., Gorong-Gorong sebagai Media...

Tabel 6. Debit Drainase Filter Beroperasi Secara Serentak

\begin{tabular}{crrr}
\hline Model Filter & \multicolumn{1}{c}{$\begin{array}{c}\text { Volume air } \\
\text { V (Liter) }\end{array}$} & $\begin{array}{c}\text { Waktu tempuh } \\
\mathbf{t}(\mathbf{d e t i k})\end{array}$ & $\begin{array}{c}\text { Debit Drainase } \\
\mathbf{Q}\left(\mathbf{m}^{\mathbf{3}} \mathbf{\text { det }}\right)\end{array}$ \\
\hline Model A & 1,48 & 10 & 0,000148 \\
\hline Model B & 1,66 & 10 & 0,000166 \\
\hline Model C & 1,64 & 8 & 0,000205 \\
\hline
\end{tabular}

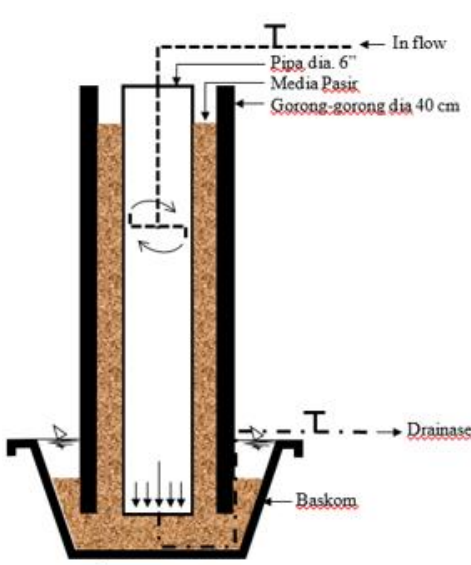

Model A

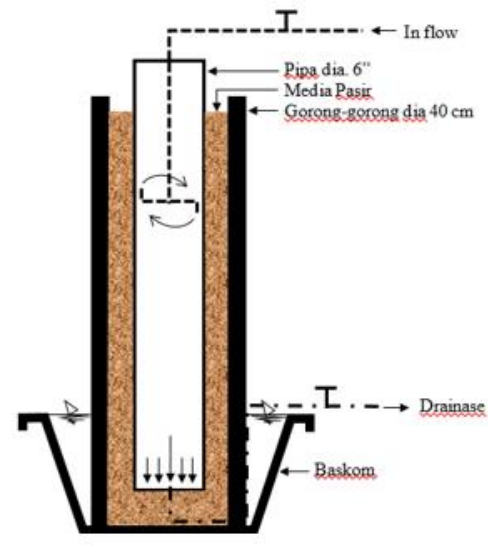

Model B

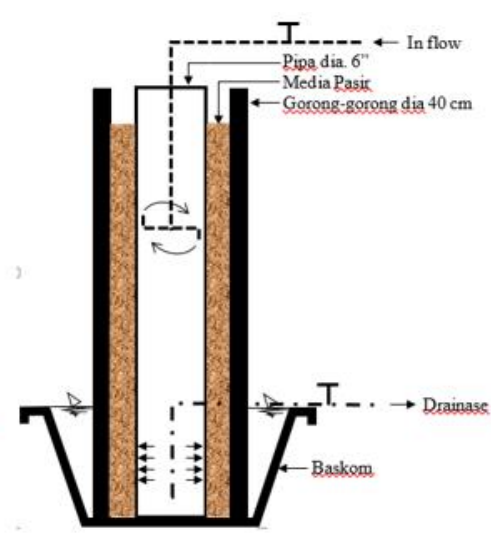

Model C

Gambar 1. Model Gorong-gorong Filter

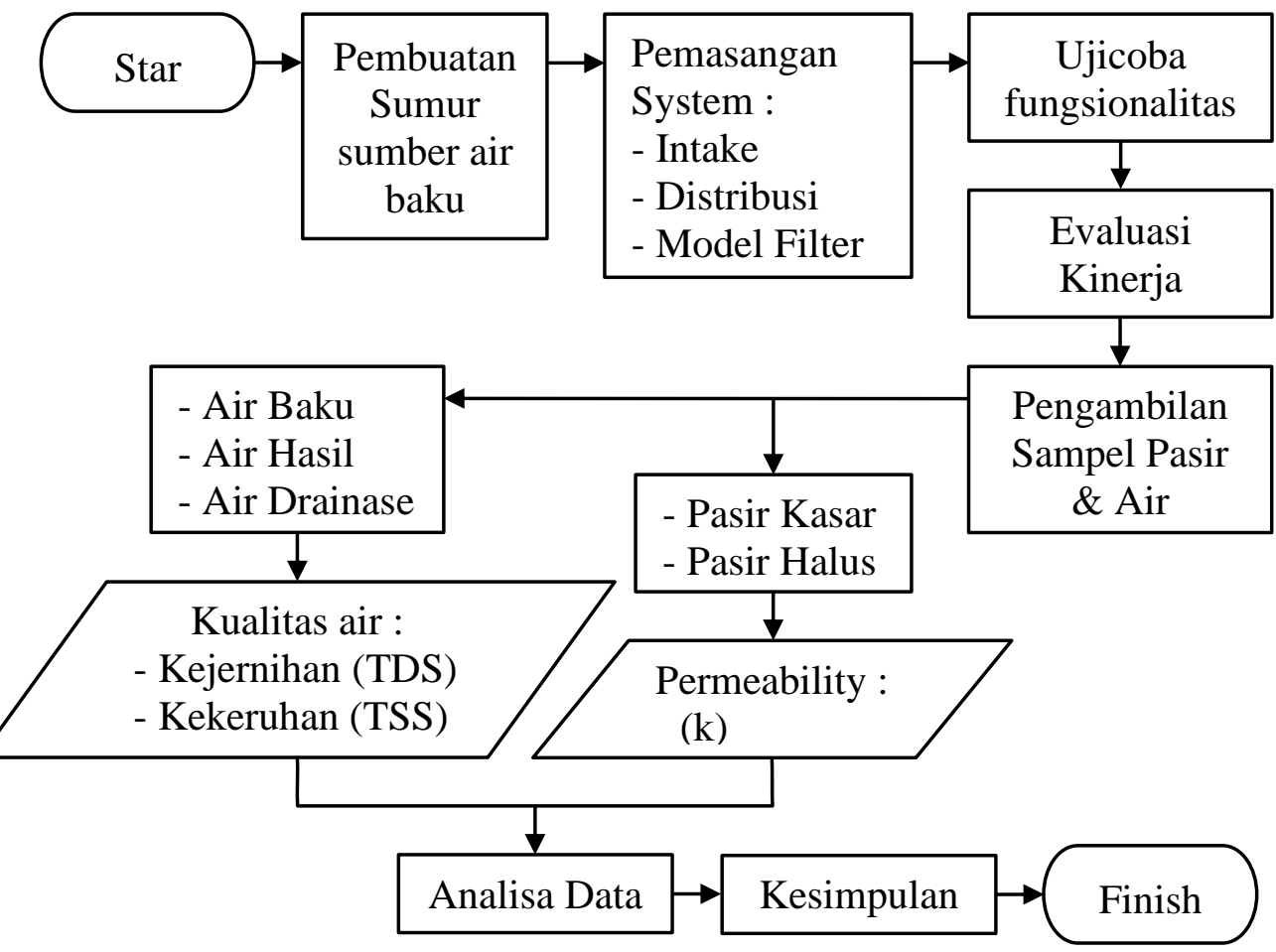

Gambar 2. Flowchart Tahapan Penelitian 


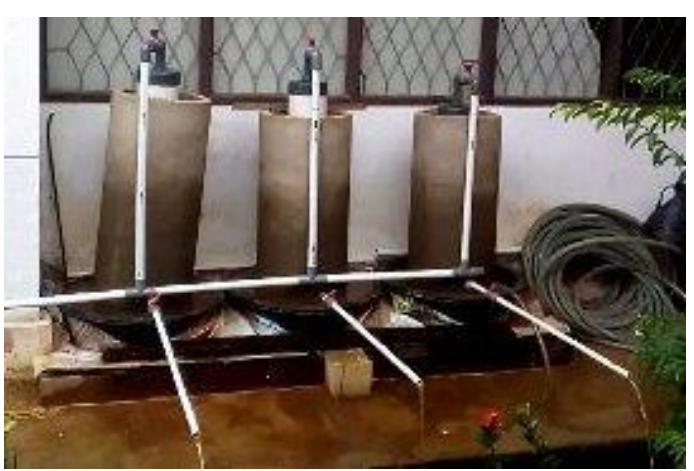

Gambar 3. System Gorong-gorong filter

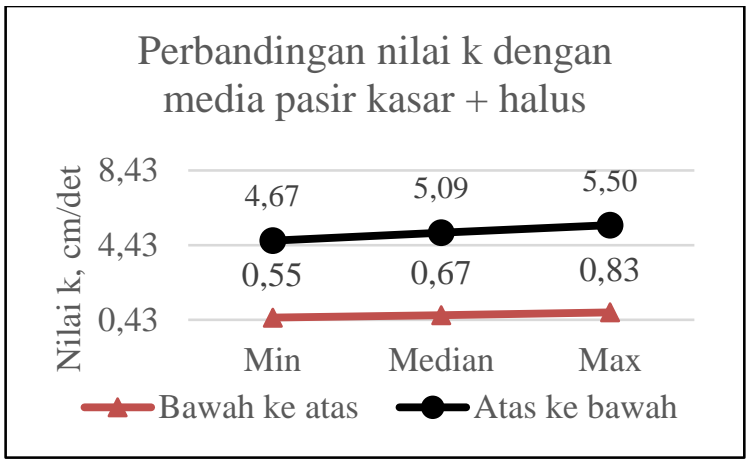

Gambar 4. Grafik Perbandingan nilai k

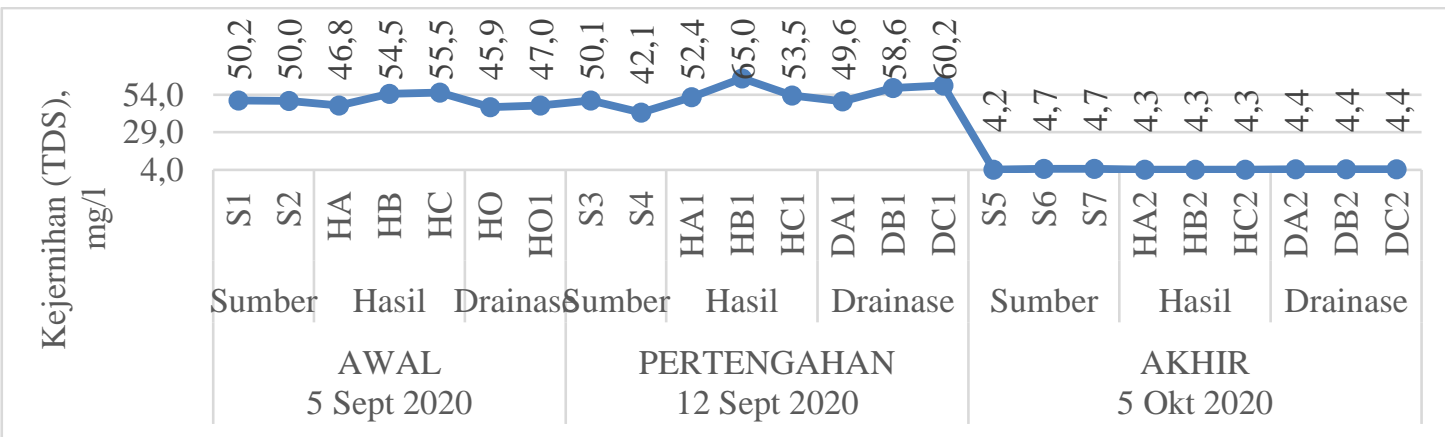

Gambar 5. Grafik Parameter TDS Per Periode

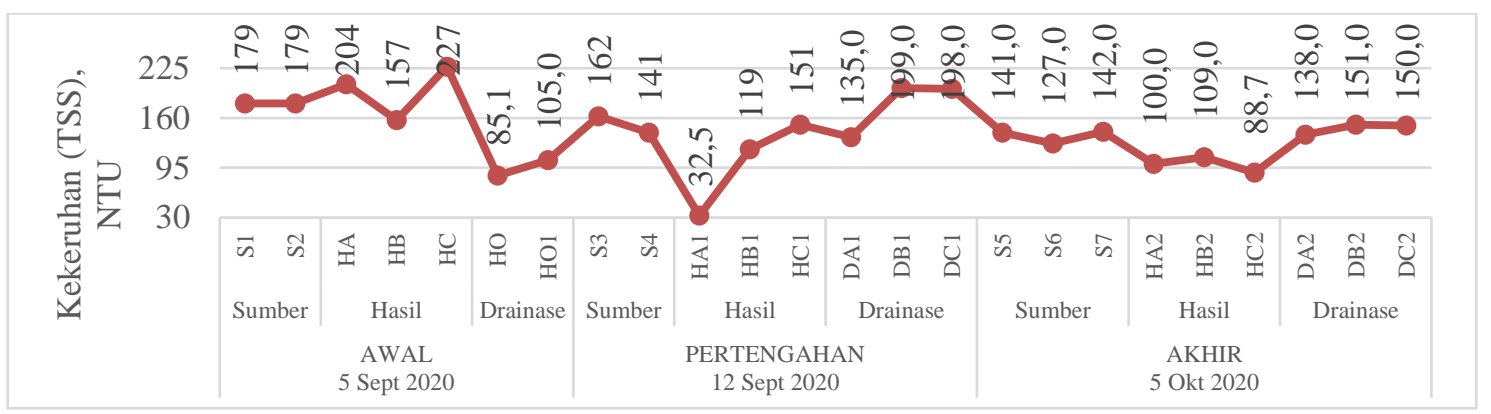

Gambar 6. Grafik Parameter TSS Per Periode

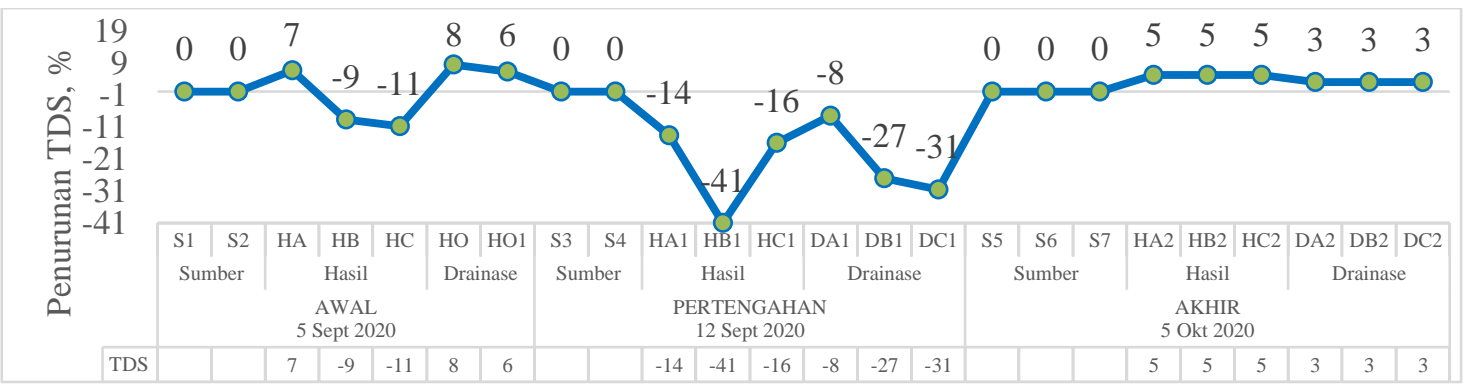

Gambar 7. Grafik Prosentasi Kemampuan Penurunan TDS

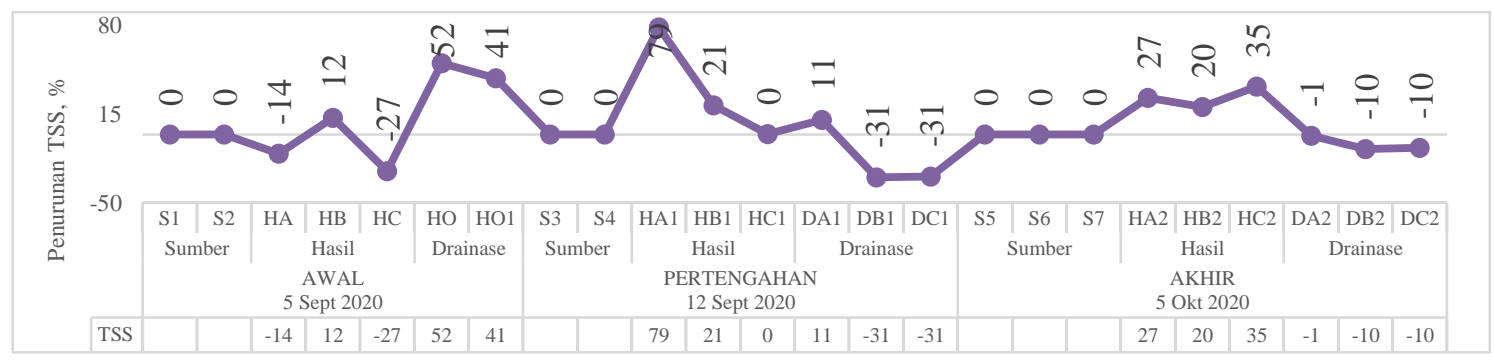

Gambar 8. Grafik Prosentase Kemampuan Penurunan TSS 